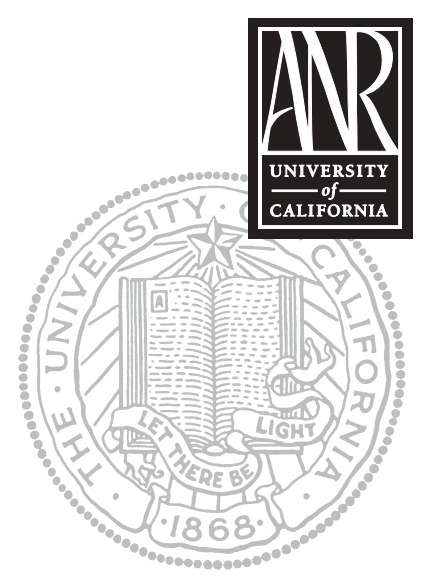

UNIVERSITY OF

CALIFORNIA

Division of Agriculture and Natural Resources

http://anrcatalog.ucdavis.edu

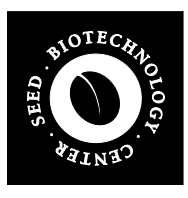

Produced by

Seed Biotechnology Center, UC Davis

http://sbc.ucdavis.edu

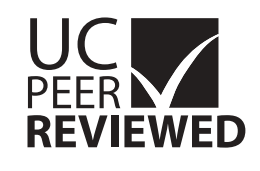

\title{
Biotechnology Provides New Tools for Plant Breeding
}

TREVOR V. SUSLOW, Cooperative Extension Specialist, Department of Vegetable Crops, UC Davis; BRUCE R. THOMAS, Technical Director, Seed Biotechnology Center, UC Davis; KENT J. BRADFORD, Professor of Vegetable Crops and Director, Seed Biotechnology Center, UC Davis

Biotechnology in its broadest sense refers to the use of living organisms or their components to provide useful products. This definition can include activities as diverse as making wine, beer, or bread; composting organic materials; releasing parasitic wasps to control insect pests; breeding plants or animals; and producing crops and livestock. In fact, agriculture itself can be considered to be the original biological technology. With increasing knowledge of genetics, plant breeders in this century have accelerated the improvement of crops for enhanced yield and quality. N ew recombinant DNA techniques now allow the specific identification, isolation, and alteration of genes and their reintroduction into living organisms to produce transgenic varieties. These new techniques are supplementing and extending traditional breeding methods to enhance the production of food, fiber, and other agricultural products. Farmers in the United States, Canada, Argentina, and other countries have rapidly adopted transgenic crop varieties. Between 1996 and 2001, the global production of transgenic soybean, cotton, corn, and canola varieties increased from essentially none to over 125 million acres ( 50 million hectares).

California's farmers produce over 350 different crops, and the state leads the nation in the production of 79 crops. California is also where the first commercial food product derived from a transgenic crop variety, Cal gene's Flavr Savr tomato, was developed and commercialized in 1994, although it is no longer on the market. Since then, commercialization and adoption of transgenic agronomic crops such as corn, soybean, and cotton has occurred predominantly in the midwestern and southern United States. Significant commercial production of transgenic cotton varieties began in California in the 1999 crop year and is increasing rapidly in acreage. Other crops are expected to follow suit in the future as transgenic traits are incorporated into additional crops that are important in California.

The introduction of transgenic crops has not been without controversy. Fears have been raised that these new techniques present unknown dangers and unacceptable risks compared to traditional methods of crop improvement. To evaluate these concerns, it is necessary to understand how modern crop varieties have been developed using plant breeding supplemented by biotechnology. This publication describes the genetic basis of crop improvement and how traditional breeding technologies compare to and integrate with the new methods.

\section{GENETIC BASIS OF CROP IMPROVEMENT}

Agricultural technology is based on the domestication of wild plants to create the crops that we have come to depend upon. Humans invented agriculture approximately 10,000 years ago when they began to harvest and cultivate specific plants to produce food. The improved plant traits selected by early agriculturalists were transmitted genetically to succeeding generations of plants. For example, domestication of corn by prehistoric 


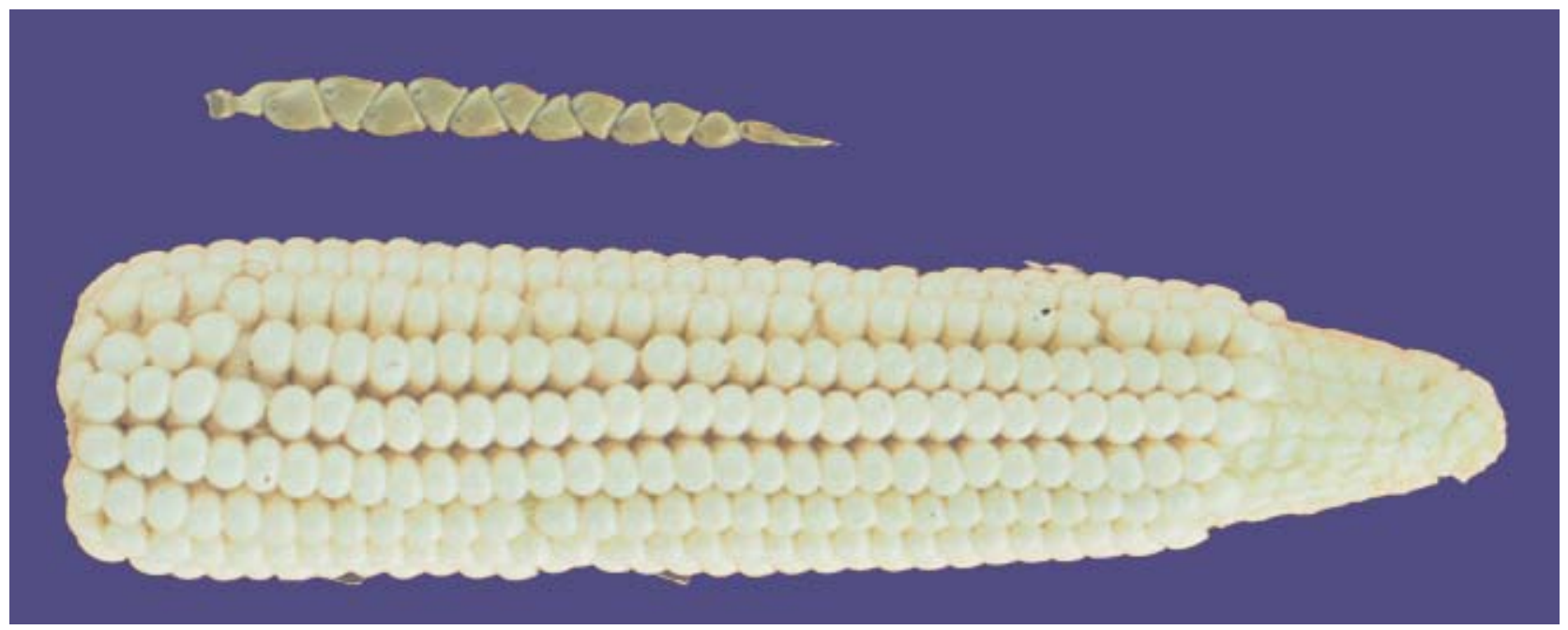

Figure 1. Domestication of corn. The upper image shows the mature inflorescence, or "ear" of teosinte (Zea mays ssp. mexicana), the probable wild progenitor of modern corn (or maize, Zea mays ssp. mays L.), shown in the lower image. The teosinte inflorescence has no cob, allowing the seed to separate and disperse easily when they are mature. Selection over time by early agriculturalists resulted in types that retained their seed on the ear, leading to the development of the cob. Modern breeding has greatly increased the size and number of seed per ear. (Courtesy J. Doebley, University of Wisconsin)

agriculturalists has modified the plant to such an extent that it hardly resembles the wild teosinte plants from which it was originally selected (fig. 1). The majority of the altered traits associated with domestication of crop plants (e.g., seed retention on the plant, easier harvesting, greater size of the harvested seeds or fruits, changes in plant form, reduction or loss of bitter and toxic substances, etc.) were al ready accomplished by the time of historic agricultural civilizations such as the Egyptian, Chinese, or Mayan. In addition, these primitive crop cultivars, also known as land races, were adapted to local growing conditions and preferences, and therefore remained genetically diverse for traits such as product qualities, stress tolerance, disease resistance, and yield stability. The domesticated plants on which our agriculture is based have resulted from the genetic modification of wild plants through thousands of years of gradual selection.

Scientific studies of genetics began around 1900 based on the work of Gregor Mendel. We now know that genes, the hereditary units, are composed of DNA (deoxyribonucleic acid) bundled together in the form of chromosomes within the nucleus of every living cell of an organism (fig. 2). (Some viruses have genomes composed of RNA, ribonucleic acid, and some organisms, such as bacteria, do not have nuclei.) All of the genetic instructions that determine an organism's characteristics are "packaged" in the genes contained in the chromosomes. These instructions are coded in the specific sequences of the four components (bases) of the DNA molecule: adenine $(A)$, thymine $(T)$, cytosine $(C)$, and guanine $(G)$.

Just as thousands of words can be made from the 26 letters of the English alphabet, the thou sands of unique genes in an organism (about 9,000 in a single-celled yeast; about 20,000 in a simple plant; about 35,000 in humans) can be spelled out using only these four letters, since a typical gene contains 500 to 2,000 bases (letters). The biological systems within the cell convert these instructions into proteins, with the DNA sequences coding for the corresponding protein (fig. 3). The activities of these proteins execute all the functions that determine the characteristics of the organism. 


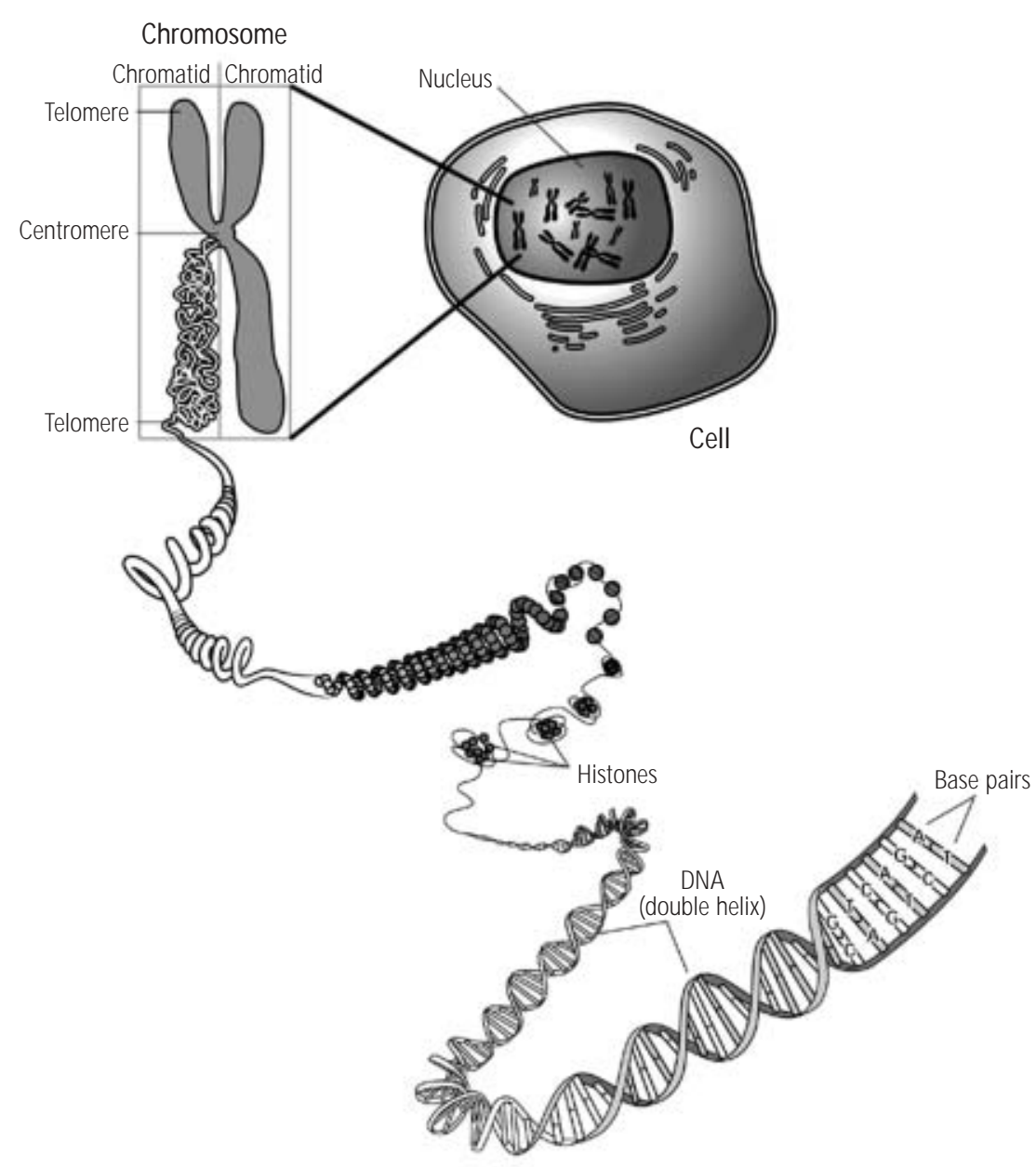

Figure 2. DNA, the basis of heredity. The DNA double helix is coiled and packed tightly with histone proteins to produce the chromosomes that are found in the nucleus of all plant and animal cells. When a cell divides, the chromosomes are duplicated and transmitted to each daughter cell. In the sexual cells (pollen and egg cells in plants), the number of chromosomes is reduced by half, and then restored to the full number when the egg and pollen nuclei combine during fertilization. (Courtesy National Institutes of Health, National Human Genome Research Institute)
Organisms that reproduce sexually contain two copies of every chromosome. During reproduction, each parent randomly transmits only one chromosome from each of its chromosome pairs to its offspring; therefore, different progeny of the same parents can vary in their genetic composition. By selecting superior individuals from each generation and using them as parents for the next generation, agriculturalists gradually developed crop varieties having more desirable traits (e.g., larger and/or sweeter fruit, higher yield, disease resistance, etc.) and fewer undesirable traits.

An understanding of genetic principles and their application to plant breeding technology has greatly accelerated the rate of improvement of our crop plants. Modern crop cultivars are more genetically uniform than the land race cultivars described above. Breeders maintain a continual search for novel genetic combinations from which to select plants with superior traits, such as crop quality, yield, regional performance, and tolerance to pests and diseases. Breeders often make sexual crosses between diverse genotypes to produce new combinations of genetic traits, which then result in diverse phenotypes, or observable morphological or quality traits in the proge-

ny plants. A primary source of genetic variation is the wide array of germplasm within each crop species and closely related wild species that are capable of interbreeding. For many crops, breeders have relied heavily on the introduction of genes from closely related wild plants to increase genetic variation in the crops (fig. 4). Hybridization between a crop plant and a related wild species (a wide cross) enables valuable genes from the wild species to be used for genetic improvement of the crop plant. For example, virtually all modern crop varieties incorporate resistances to fungal, bacterial, and viral diseases that have been introduced through wide crosses between domesticated varieties and related wild species (introgression). Genetic variation can al so be increased by inducing mutations, or changes in the DNA sequences of the plants. Since the 1950s, over 2,000 crop varieties have been developed by inducing mutations to randomly alter genetic traits and then selecting among the progeny for improved types.

Specific hybridization methods are also used to increase crop uniformity and yield. Scientists discovered in the 1920s that if some plants, such as maize, were continually 
crossed with themselves (self-pollinated or inbred), their vigor would quickly decline over several generations. However, if two distinct inbred plants were crossed together, the resulting progeny (called F 1 hybrids) often exceeded both parents in vigor and yield. This phenomenon, known as hybrid vigor or heterosis, is the basis of a large hybrid seed industry for maize, sorghum, sunflower, and many vegetables. Producing hybrid seeds requires genetic manipulations to develop the inbred parents. A specific cross is then made between the two parents to produce the F1 seed that is sold to the farmer. Plants growing from those seeds exhibit the desirable hybrid vigor to produce the commercial crop, but the subsequent generation (F2) loses this advantage due to the random assortment of the traits from the two parents among the individual progeny, in accordance with the principles of genetics. This means that farmers must purchase new seed each year in order to receive the higher yield and other benefits that the hybrid crop provides.

Regardless of the method by which genetic variation is introduced or managed, diverse progeny must be tested extensively to identify the superior plants that will be propagated and used for commercial pro-

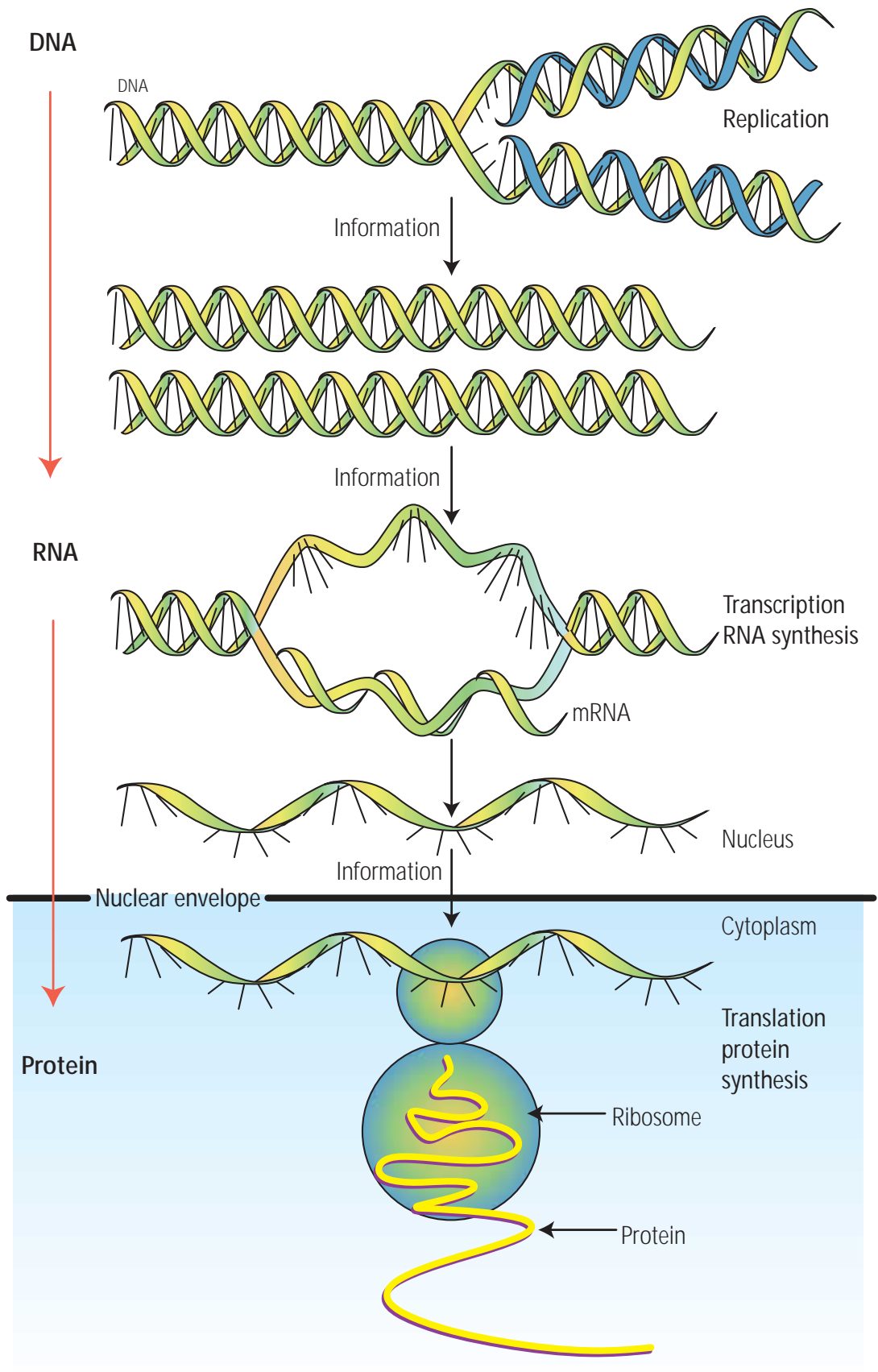
duction of food or fiber. Every year breeders test large populations of plants using various techniques (e.g., mass selection, line breeding, family breeding, recurrent selection, etc.) depending on the crop species and the mode of inheritance for the desired traits. Generally, only a very small percentage of the plants tested exhibit improved traits and are therefore retained to be parents for the next generation. In combination with improved agronomic practices, genetic improvement of crop varieties has led to dramatic increases in crop yield and quality. It is generally estimated that about half of the total increases in crop yield in the past 50 years are the

Figure 3. Information in DNA sequences codes for specific proteins. The sequence of subunits $(A, T, G$, and $C$ ) in DNA molecules carries the information needed for cellular function. When cells divide, the DNA molecules are duplicated so that the information is transmitted to all subsequent cells. The information in the DNA is "read" by the synthesis (transcription) of RNA molecules that have a sequence of bases complementary to that in the DNA molecule. The RNA molecules then leave the nucleus and move to the cytoplasm of the cell, where the ribosomes translate the sequence of bases in the RNA into a specific sequence of amino acids that constitute a protein. In this way, the information in the DNA sequences directs the synthesis of the thousands of different proteins that living cells require. 
result of genetic improvements, the other half being due to improved management techniques (fertilization, irrigation, pest and disease control, etc.).

Both public institutions (e.g., land-grant universities, USDA) and private companies are involved in crop genetic improvement. Private investment in plant breeding has been stimulated by legal mechanisms to allow the developer to retain commercial rights to the sale of the resulting variety. Since 1930, the U.S. Plant Patent Act has allowed breeders to obtain patent protection for plant varieties developed in many ornamental, tree, and vine crops that are propagated vegetatively (i.e., by cuttings or buds). The Plant Variety Protection Act of 1970 established breeders' rights for devel opment of plant varieties propagated by seed, and general utility patents (i.e., as for other types of inventions) can also be awarded for improved plants. These laws are intended to prevent unauthorized propagation and sale of protected varieties, much as copyright laws prevent copying of books or music without a license from the owner. In addition, F1 hybrid varieties offer a biological protection method because they cannot be propagated by simply saving seed from the commercial crop, as is possible with many self-pollinated varieties such as soybean, wheat, or cotton.

\section{ADDITIONAL TOOLS FOR PLANT IMPROVEMENT}

The plant breeding methods described above have enabled remarkable improvements to be made in the yield and quality of our modern crops. Additional tools are also used for genetic enhancement and propagation of crop plants. As with plant breeding, these methods have been used for many years to develop crop plants that better suit our needs.

\section{Grafting and tissue culture techniques}

Grafting of tissues from two different varieties of a plant species has been used since ancient times in woody tree and vine crops such as citrus, peaches, walnuts, grapes, and ornamental trees. Surgically cutting a scion or bud from one variety and grafting it onto a rootstock from a different genetic variety is commonly used to enhance the disease resistance, productivity, and growth habit of these perennial crops. Superior varieties, often developed through chance or induced mutations as well as through sexual crosses, can be rapidly and uniformly propagated by grafting buds onto the rootstocks of other varieties.

Tissue culture has been used in crop improvement since the 1940s. In the simplest cases, this refers to culturing embryos or small plants in the laboratory on specific nutrient media until they can be moved into soil. The tiny growing tips of plants (meristems) can also be grown in culture to produce entire plants. In addition, plants have the unique property of being able to regenerate an entire plant from a single cell (totipotency). Under carefully controlled conditions, tissues can be taken from a plant, separated into individual cells that are grown in the laboratory as callus, then induced to develop back into whole plants (regenerate). These techniques have been used in a number of ways in crop propagation and improvement.

M icropropagation is the production of multiple copies of a single plant using tissue culture techniques (fig. 5). Often, the tissue used is the meristem, where new leaves and stems are produced. Each growing tip on a plant can be excised and grown into a complete new plant. In many cases, viruses that infect a plant are not present in the growing tip, so viruses that have infected the parent plant are eliminated from plants produced by micropropagation. For example, potatoes are normally propagated by planting the buds, or "eyes," present on the tubers, and garlic is propagated by planting cloves from last year's crop. This method of propagation allows viruses to be transmitted to the 


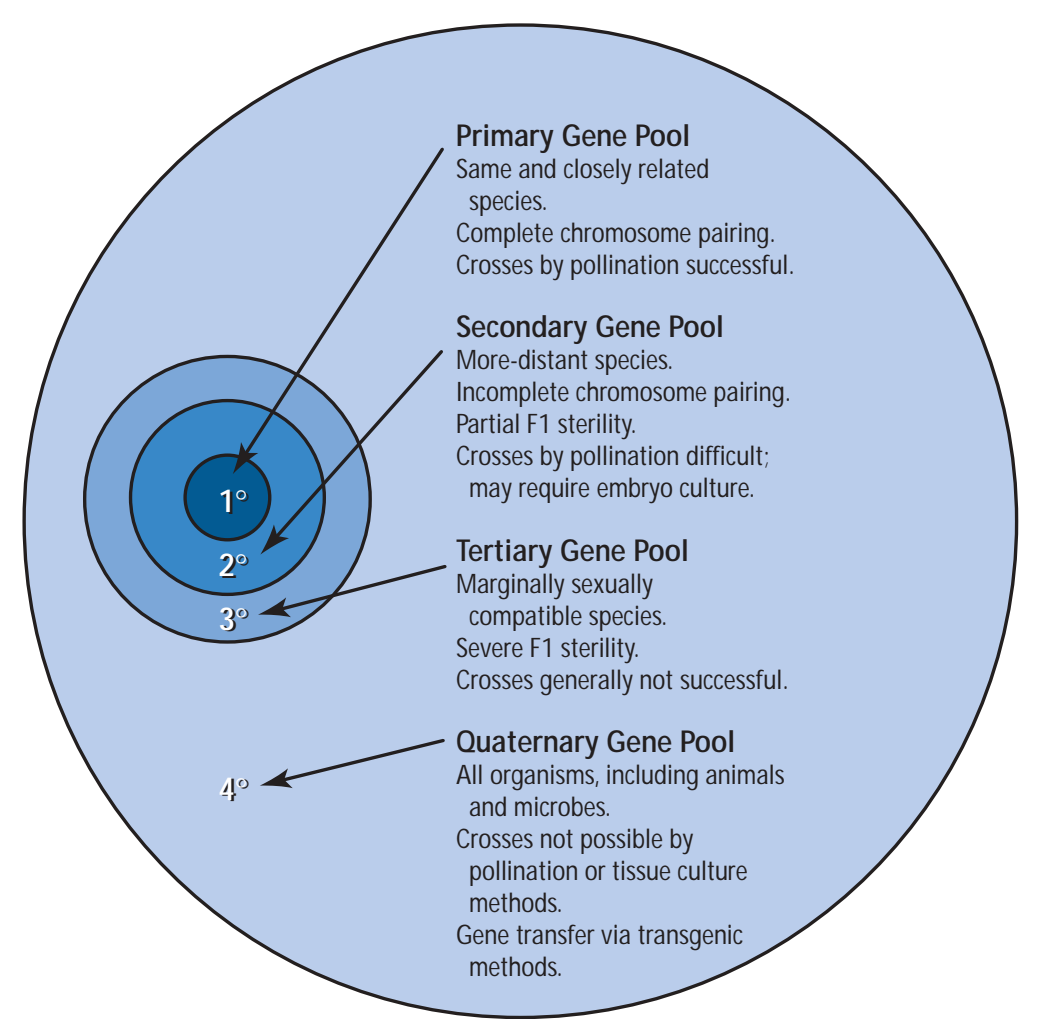

Figure 4. Sources of genetic variation for crop improvement. Breeders produce plants with improved combinations of genes by crossing (hybridization) and selection within the primary gene pool, which is comprised of a crop species and its closest related wild species. Tissue culture methods such as embryo culture are commonly used to enable genes from the secondary gene pool to be transferred into the cultivated species. Other methods such as somatic hybridization sometimes allow genes from the tertiary gene pool of more distantly related species to be transferred into crop plants. The immense gene resources of the quaternary gene pool (essentially all other organisms) can be used for crop improvement only via transgenic methods. new crop each year, resulting in diseased plants and reduced yields. Micropropagation of potato and garlic plants in the laboratory can eliminate virus diseases and ensure that each new crop is planted with virus-free materials, greatly increasing yields. Micropropagation has been the starting point for each new cycle of strawberry plants grown in California for over 20 years both in commercial fields and home gardens. Micropropagation is also used in asparagus and other crops to multiply individual superior plants to create parent plants used in production of hybrid seed. Many ornamental plants (e.g. orchids and gerbera) are now almost exclusively propagated in this way.

Embryo culture has been used to rescue hybrid plants from wide crosses, which often fail to produce mature viable seeds. In these cases the immature embryo tissue can be removed from the developing seeds and cultured in the laboratory to produce the hybrid plants. Embryo culture enables the breeder to successfully make wide crosses with a greater number of related species of wild plants and have access to a much wider range of genes that can be used for genetic improvement of crop plants. Wide crosses and embryo culture have been valuable tools, especially for the transfer of disease resistance genes from wild relatives into crop plants.

Anther culture is a specific application of tissue culture used in the production of F1 hybrid varieties. The first step is to develop inbred parent lines by repeated self-pollination. This can be a very slow process in some crops, such as onions or carrots, which normally require 2 years to flower. However, by culturing pollen grains in the laboratory, haploid plants that contain only one copy of each chromosome can be produced. These plants can then be induced to double their chromosome number by a chemical treatment, quickly resulting in plants that have two identical sets of chromosomes, or are completely inbred (homozygous). This procedure can dramatically reduce the time required to develop inbred parents for breeding of $F 1$ hybrid varieties and facilitates the selection of recessive traits.

Cell culture (callus) can also be used to produce multiple embryos that can be grown into plants. In this way, a virtually unlimited number of plants can be propagated from a single superior plant. However, somaclonal variation somewhat limits the application of cell culture for plant propagation. Somaclonal variation is genetic variation that occurs in a small fraction of cells in a callus culture. Most plants regenerated from callus are genetically identical to the original plant from which the callus was derived, but a small fraction of the resulting plants may exhibit genetic changes. While this is a problem for the clonal propagation of identical plants, it has been exploited as a new method to increase genetic variation. For example, carrot and pepper varieties with better eating quality have been selected among plants derived from callus culture. 


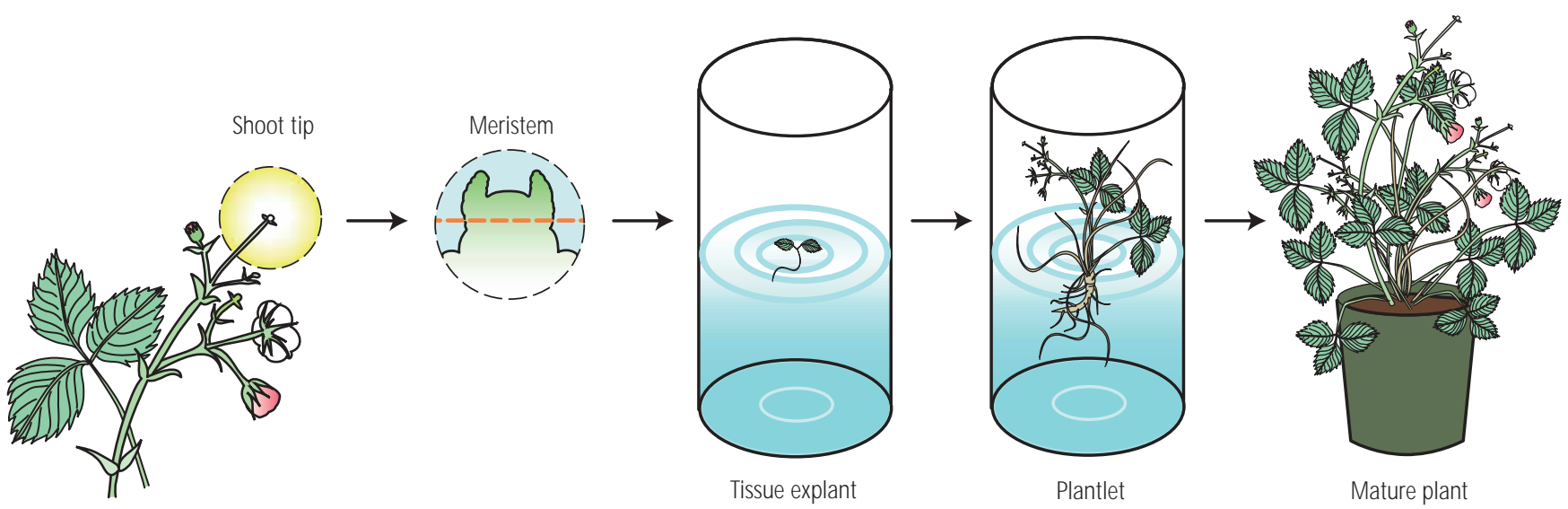

Figure 5. Micropropagation of plants via tissue culture. Shoot tip meristems (the microscopic growing tips of shoots) can be dissected and grown in tissue culture to produce small plants that can then be transferred to soil and eventually to the field. This method is used extensively to propagate strawberries, potatoes, garlic, and many ornamental plants. In addition to multiplying the original plant, this method often is effective in eliminating diseases.

Protoplast fusion is another method for producing new genetic variation in the laboratory. A protoplast is a plant cell from which the rigid outer cell wall has been removed using enzymes. Under certain conditions, protoplasts derived from genetically different plants can be fused much like two soap bubbles, allowing their DNA (and other cellular contents) to be combined. The fused cells can then be induced to regenerate into whole plants, which will have traits derived from both parents. Some novel Chinese cabbage varieties developed through protoplast fusion have been marketed. Protoplast fusion has also been used to transfer male sterility (lack of pollen viability) from radishes into other Brassica species (cabbage, cauliflower, broccoli, canola), where it is used in the production of $F 1$ hybrid seeds.

\section{Marker-assisted breeding and genomics}

M arker-assisted (or molecular-assisted) breeding provides a dramatic improvement in the efficiency with which breeders can select plants with desirable combinations of genes. A marker is a "genetic tag" that identifies a particular location within a plant's DNA sequences. Markers can be used in transferring a single gene into a new cultivar or in testing plants for the inheritance of many genes at once. Markers can be based upon either DNA or proteins. DNA markers identify locations where the sequences differ among varieties or breeding lines. These can be locations within genes or in the DNA between genes, so long as they are unique sequences and differ between the plants of interest. Differences of this type are called polymorphisms, and there are a variety of ways to detect and use these signposts within the chromosomes.

Protein markers are based on differences in the proteins that are synthesized from the genes. Enzymes are proteins that catalyze specific biochemical reactions and can therefore be assayed for their activity. Plants often contain multiple copies of the same enzyme that differ slightly in size or charge, making it possible to separate them from each other. These are known as isozymes, and their sizes often differ among different genotypes (fig. 6A). In these cases, the genes coding for the specific isozyme can be identified by following the inheritance of the isozyme. Abundant proteins that are not enzymes, such as the seed storage proteins of cereal grains, can also be separated and stained to reveal specific size patterns characteristic of different genotypes.

Both DNA- and protein-based markers have been widely used in plant breeding, but DNA-based markers are expected to predominate in the future (fig. 6B, C). Greater numbers of DNA-based markers can be identified to cover all regions of an organism's 
DNA, and they are not based on the developmental stage of the plant, as many proteinbased markers are. DNA-based markers can be visualized from seeds or seedlings in rapid screening tests, performed by automated robotic systems in advanced applications, and plants lacking the desired trait can be discarded before moving to more expensive or lengthy greenhouse and field trials.

When transferring a specific desirable gene from a wild plant into a crop plant via wide crosses, the simultaneous transfer of undesired genes from the wild plant is often a problem. In repeated crosses to the cultivated type, the percentage of wild type genes in each generation would be $50 \%$ in the first generation, $25 \%$ in the second, $12.5 \%$ in the third, $6.25 \%$ in the fourth, etc. Even after many generations, wild-type genes located close to the desired gene on the chromosome may still be present (i.e., are closely linked to the desired gene). Marker-assisted breeding is helpful to identify plants that have inherited the desirable gene together with as few of the undesired genes as possible. One can think of the desired gene as the "needle in the (genetic) haystack." Traditional methods require sorting through the entire haystack to find the needle, while markers provide a "metal detector" to easily find the specific part of the haystack where the needle is located.

A

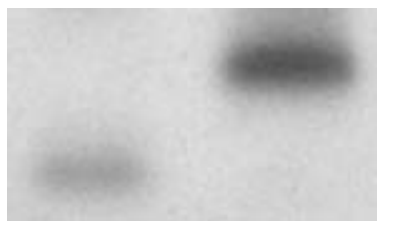

B

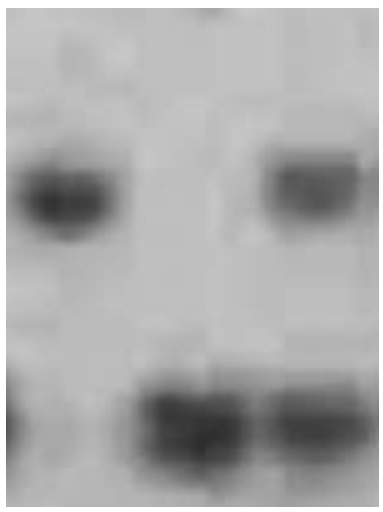

C

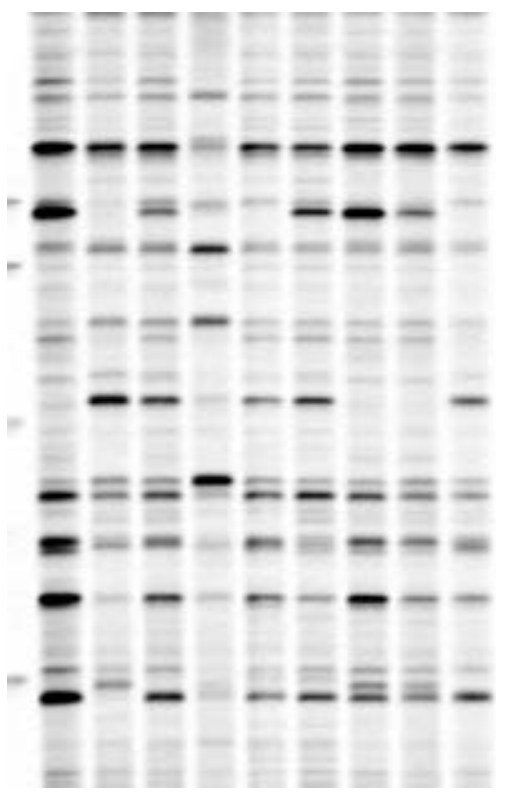

For example, an isozyme

D

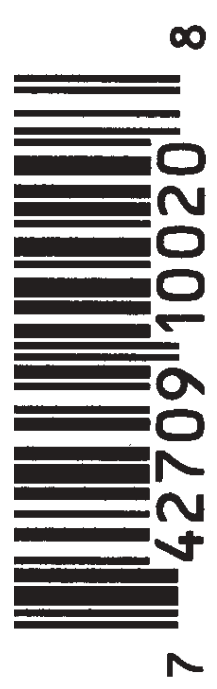
marker speeded the development of commercial tomato varieties containing the $\mathrm{Mi}$ gene (which confers resistance to the root knot nematode, a serious worldwide pest). The $\mathrm{Mi}$ gene was originally discovered in a wild relative of tomato and was transferred into cultivated tomatoes by sexual crosses and embryo rescue. Progress was slowed by the difficulty of screening for nematode resistance, which required that each plant be planted in soil infested with the nematodes, grown to maturity, and then examined

Figure 6. Molecular markers identify specific genes. Molecular markers identify specific proteins or DNA segments that are associated with a particular trait. (A) An isozyme marker based on different forms of the same enzyme present in different parents. In this case, the lower band representing acid phosphatase activity is linked to the nematode resistance Mi gene, while the upper band is present in susceptible plants. When parent lines are crossed, simply assaying each progeny plant to determine which isozyme it contains can identify those carrying the resistance gene. (B) DNA-based markers identify specific sequence regions of the DNA itself. Restriction fragment length polymorphisms (RFLP) shown here can identify which form of a gene is present in a plant, or whether the plant contains both forms on different chromosomes. In this case, the lower band is linked to a gene that produces high sucrose content in tomato fruit while the upper band indicates that the fruit will have normal sugar content. When both bands are present, the plant inherited one gene of each type from its two parents. (C) Another type of DNA-based marker, sequence-related amplified polymorphisms (SRAP), can simultaneously identify many different locations in the genome. New techniques such as these allow hundreds or even thousands of DNA locations in the genome to be identified in individual plants. (D) M olecular genetic markers can be thought of like the Universal Product Code (UPC) barcodes. A computer database in the grocery store links the complex pattern of the UPC barcode to information such as supplier, inventory, and cost of the labeled item. In a similar way, plant breeders can read the information from molecular marker patterns to know which specific genes are present within a given plant. 
for infection. Later, it was discovered that a gene encoding a particular isozyme from the wild parent was located on the chromosome immediately adjacent to the Mi gene. This isozyme marker had been transferred together with the $\mathrm{Mi}$ gene in the original sexual crosses. As these genes were very close neighbors in the tomato DNA, virtually all plants that inherited the $\mathrm{M}$ i gene al so inherited the isozyme marker. Once this linkage was discovered, breeders could predict whether an individual plant had inherited the Mi gene simply by testing which plants expressed the associated isozyme marker (see fig. 6A). Tests for the isozyme marker can be conducted quickly on very small seedlings, so only plants carrying the linked $\mathrm{Mi}$ gene needed to be grown to maturity. By using markers to speed the job of identifying plants that contained the M i gene, breeders could focus their efforts on identifying plants with improved horticultural traits that did not inherit any undesirable genes from the wild tomato.

DNA markers are useful to test plants for inheritance of many different genes simultaneously. A simple way to appreciate this powerful tool for selection of improved crop plants is to visualize the UPC barcodes found on most products in the supermarket (fig. 6D). The band pattern of the UPC code uniquely identifies the product and can be linked to a database of product traits such as cost, supplier, inventory, etc. In a similar manner, the pattern of DNA markers (fingerprint) allows the breeder to identify both desirable and undesirable genes that the plant may contain. As the number of traits (genes) that are desired increases, the number of plants that must be screened to identify plants that have the rare superior combinations of genes increases even more rapidly. By providing quick and efficient tests for many different genes, DNA markers are being widely used in breeding crop varieties having optimal combinations of desirable genes. DN A markers have been used for transferring pest resistance genes to cultivated varieties, assisting selection of complex multigene traits (such as flavor), aiding evaluation of regionally and seasonal ly optimized varieties, allowing genetic purity testing, and enabling proprietary variety protection and patent enforcement. For more information, see "Fingerprinting" Vegetables: DN A-based M arker Assisted Sel ection, Vegetable Research and Information Center (http://vric.ucdavis.edu/veginfo/biotech/fingerprintveg.pdf).

\section{RECOMBINANT DNA TECHNIQUES}

\section{DNA cloning techniques}

Plant traits are encoded in the DNA of their genes. In 1973 it became possible to identify and multiply specific DNA molecules, based on discoveries by researchers at the University of California and Stanford University. They developed methods for isolating specific segments of DNA molecules, inserting them into other DNA molecules (or vectors), and using bacteria as "biological copy machines" to produce large quantities of these DNA molecules. These recombinant DNA techniques enable researchers to isolate genes from any organism, amplify (or clone) them in large quantities, and study their characteristics and functions (fig. 7). These techniques rely on restriction enzymes (such as EcoRI) that can recognize specific DNA sequences and cut the DNA strands at those sites. The ends of the DN A are cut unevenly, leaving an overhanging strand on each end. These are known as "sticky ends" because they are able to match up with other DNA strands that have complementary base sequences. Thus, if the same enzyme cuts two different DNA molecules, the ends of the molecules can match up and then be rejoined by another enzyme, DNA ligase. In this way, specific segments of DNA molecules can be cut and rejoined in different combinations. It is this ability to recombine different DNA molecules in the laboratory that leads to the term recombinant DNA technology.

In practice, a desired gene is cut from the DNA molecule using restriction enzymes and is inserted into a vector molecule that is then introduced into bacterial cells (see fig. 


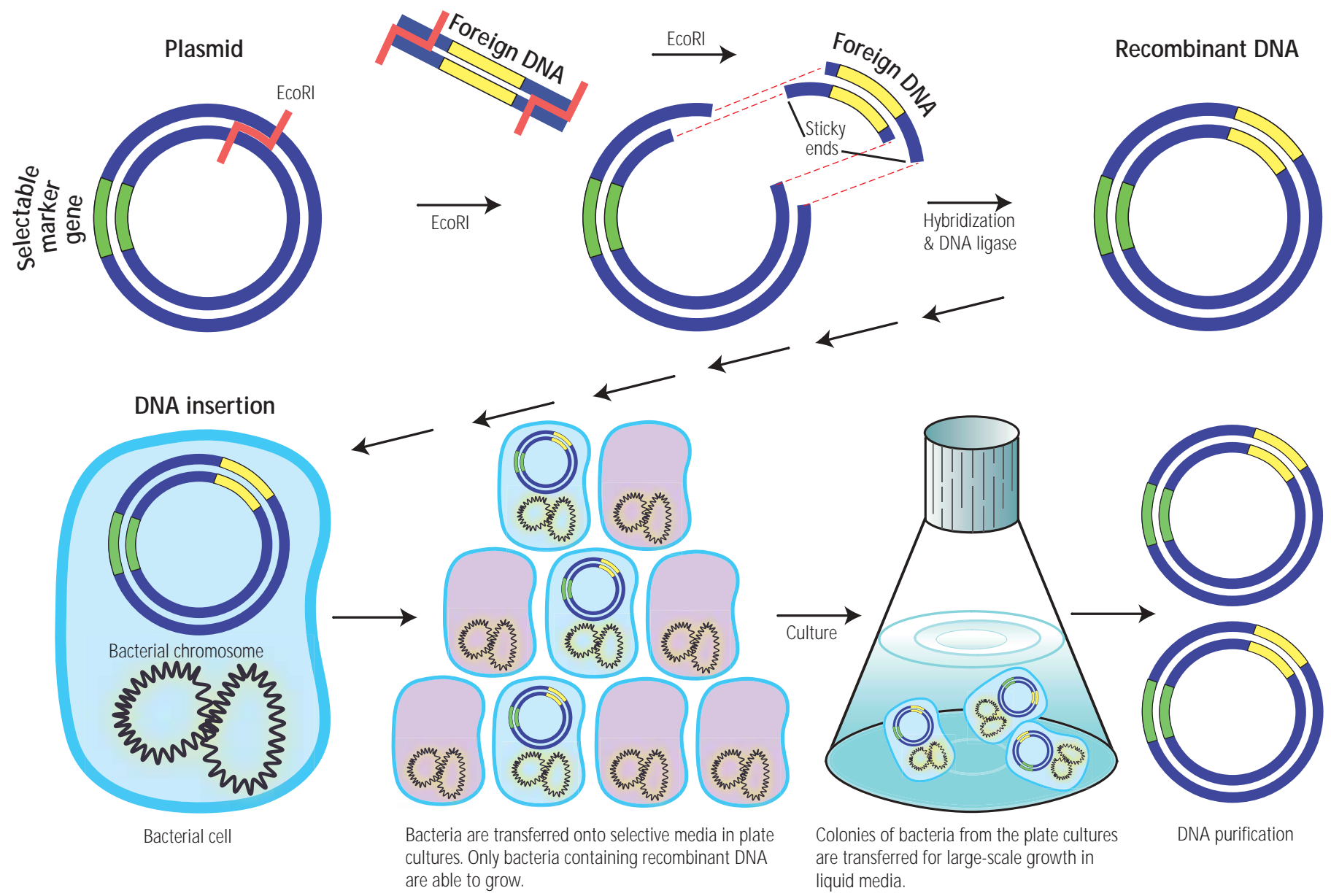

Figure 7. Recombinant DNA techniques and DNA cloning in bacteria. A plasmid, or circular piece of DNA that can replicate in bacterial cells, is used in DNA cloning. It generally contains a selectable marker gene that, for example, makes cells resistant to an antibiotic. Both the plasmid and the DNA containing the foreign gene of choice are treated with a restriction enzyme (e.g., EcoRI) that cuts the DNA in specific locations and leaves "sticky ends" overhanging each strand that will match up and can be rejoined using DNA ligase enzyme. Inserting the plasmid, now containing the foreign DNA, into a bacterial cell enables those cells to grow in the presence of the antibiotic. As these cells grow and multiply, they also copy the plasmid, making large quantities of the foreign DNA as well. The recombinant plasmid DNA can then be purified to recover the multiplied foreign DNA.

7). The vector DNA (or plasmid) is reproduced as the cells grow and multiply, making many copies of the inserted DNA. In addition, the plasmid incorporates a separate gene that confers resistance to an antibiotic only to those cells containing the plasmid. Thus, if the cells are grown in a medium containing the antibiotic, only those cells having an intact plasmid, and thus also incorporating the transferred, or cloned, gene, will be able to survive. This selectable marker is essential to identify only the cells that contain the plasmid vector and allow them to multiply. The cells can then be harvested and the DNA can be extracted and purified to obtain large quantities of the desired gene.

To illustrate the basic concept of recombinant DNA methods, think of DNA as the biological equivalent of videotape (fig. 8). The instructions organisms need to grow and function are encoded on linear pieces of DNA, just as images are encoded magnetically in the linear pieces of videotape. When the videotape is played, the encoded information is converted electronically into the scenes displayed on the TV screen. Similarly, celIular machinery reads the DNA and converts the genetic information into proteins, which then carry out the functions necessary for life. Because DNA is chemically similar among all organisms, the instructions on these cloned pieces of DNA can be readily exchanged and "understood" between organisms as dissimilar as yeast and tomatoes. Just as technicians can cut, copy, and splice sections of videotape to create new scenes, 

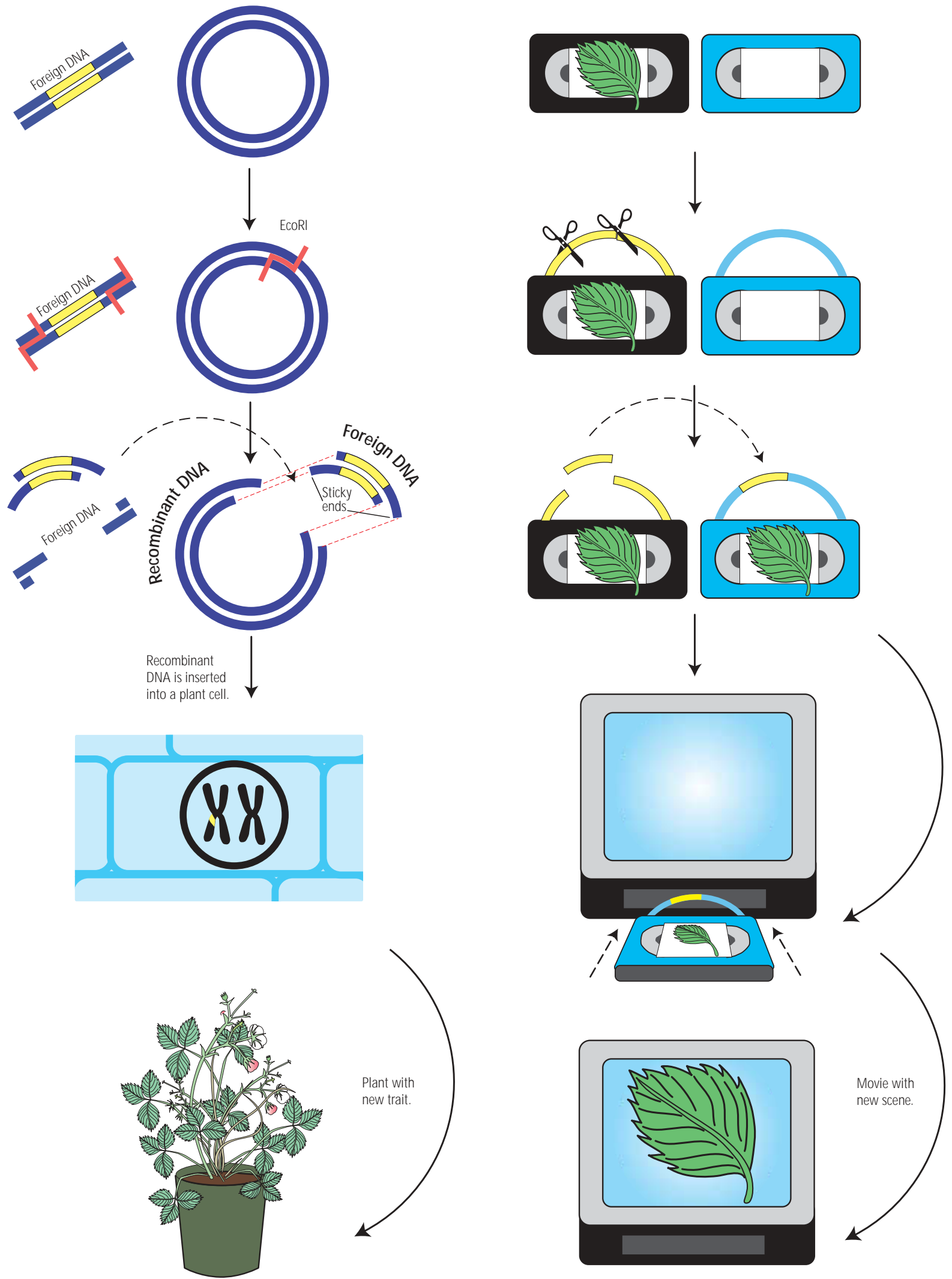

Figure 8. Recombinant DNA is analogous to videotape editing. DNA sequence information encodes genes that determine the characteristics of an organism just as videotape contains the information that can be used by a videocassette player to display a movie on the screen. Recombinant DNA methods allow a segment of DNA to be transferred from one organism to another, thereby transferring the trait that the gene encodes. Similarly, a section of videotape containing a specific scene can be cut and spliced into a second tape, which will then display the transferred scene. 
scientists can now copy and exchange genes among organisms to introduce new characteristics. In theory, any gene from any organism is potentially transferable to other organisms by recombinant DN A techniques, although this has been achieved in practice only among relatively few organisms. The inserted gene may give the organism the ability to do something that it could not do without the gene, such as resist attack by pests or produce a vitamin. Recombinant DNA techniques have essentially made all genes (i.e., the quarternary gene pool; see fig. 4) available to plant breeders for crop improvement, not just those found in a given species or its close relatives.

The ability to isolate segments of DNA and to determine the sequence of the component bases (adenine, thymine, cytosine, guanine) in them has resulted in an explosion of biological information. Genome projects determine the DNA sequences for all of the genes in an organism. Information from the recently completed Human Genome Project is expected to yield breakthroughs in our understanding of human diseases and new therapeutic treatments. The genomic sequence for the model plant Arabidopsis thaliana was completed in December 2000 (see The Arabidopsis Information Resource, http://www.arabidopsis.org/), and genome projects are in progress for a number of major crop plants (see USDA Plant Genome Data and Information Center, http://www.nal.usda.gov/pgdic/). These projects are revealing a remarkable similarity among the genes coding for specific proteins not only across most plants, but also in some cases across plants, animals, and microorganisms. These results demonstrate a fundamental consistency and conservation in the basic machinery of life.

\section{Transformation techniques}

Once genes have been cloned, they can be transferred into the same or a different organism, producing a transgenic individual. Because of the simple genetic makeup of bacteria, transferring cloned genes into them is relatively easy. Thus, the first applications of recombinant DNA technology were to introduce useful genes into bacteria. The first transgenic organism patent was issued in 1981 for a bacterium engineered to break down hydrocarbons. Now, a majority of all cheese is made using chymosin, an enzyme purified from microbes expressing a cloned chymosin gene, rather than using rennet extracted from calf stomachs. Most of the insulin used in human therapy for diabetes is produced by expressing the human insulin gene in microbes. Many other pharmaceuticals are manufactured in fungi, insect, or mammalian cells engineered to produce specific proteins.

Transfer of cloned genes into plants (transformation) is somewhat more difficult than transfer into bacterial and animal cells, but it can be accomplished by several methods (fig. 9). The most commonly used transformation method employs the bacterium Agrobacterium tumefaciens to transfer the desired DNA into the plant. When it enters a plant through a wound, this bacterium naturally transfers part of its DNA into the plant's chromosomes. These bacterial genes cause the plant to make a structure to house the bacterium (a gall) and produce unique compounds that the bacterium consumes. In the 1980s, scientists discovered how to use Agrobacterium to transfer cloned genes into plant chromosomes while preventing the formation of galls. Desired genes can be spliced into the bacterial DNA, and then Agrobacterium, like a video editor, transfers them into the plant's chromosomes. A second approach for production of transgenic plants, known as biolistics, coats the desired DNA onto microscopic metal beads and then fires these at high speed into pieces of plant tissue. The beads deliver the DNA into the plant cells, some of which will incorporate the DNA into their chromosomes. The transgenic cells resulting from these processes can be selected and regenerated into whole plants by tissue culture. These plants will then express the characteristics encoded by the cloned genes (see Center for Engineering Plants for Resistance Against Pathogens, http://ceprap.ucdavis.edu/Transformation/transform1.htm). Transgenic plant methods 

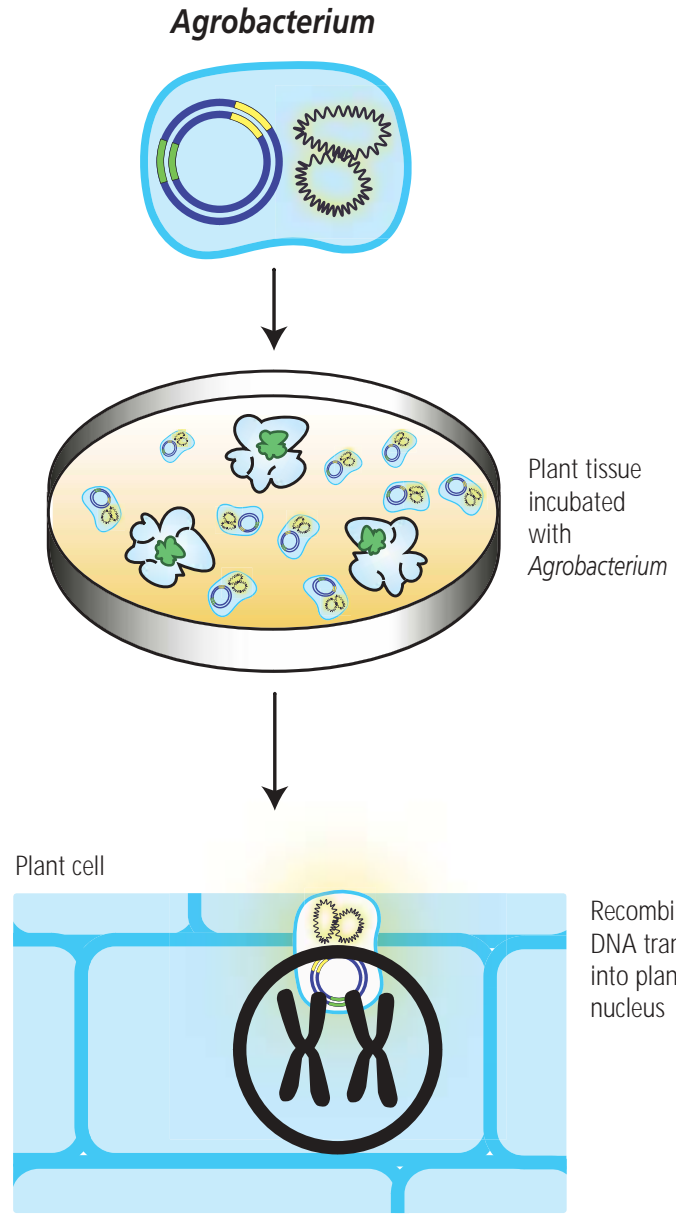

Recombinant DNA transferred into plant nucleus

\section{Recombinant DNA coated onto microcarriers}
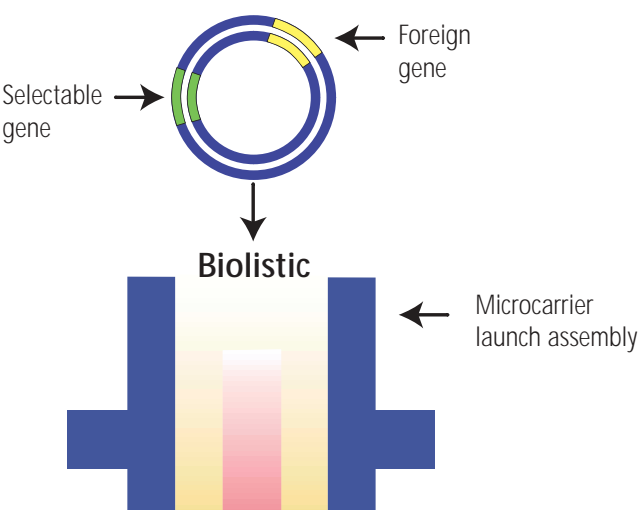

DNA-coated microcarriers propelled into plant cells

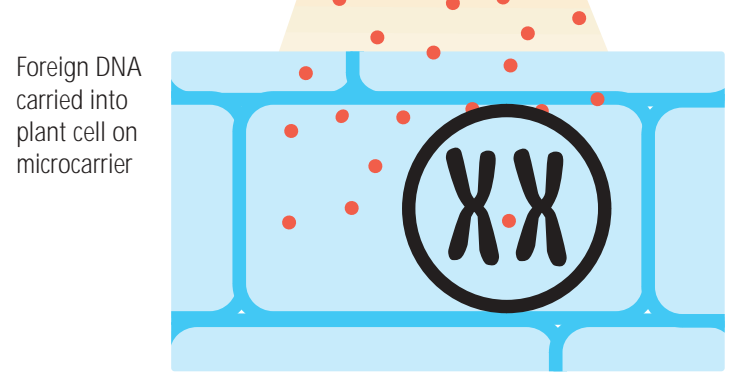

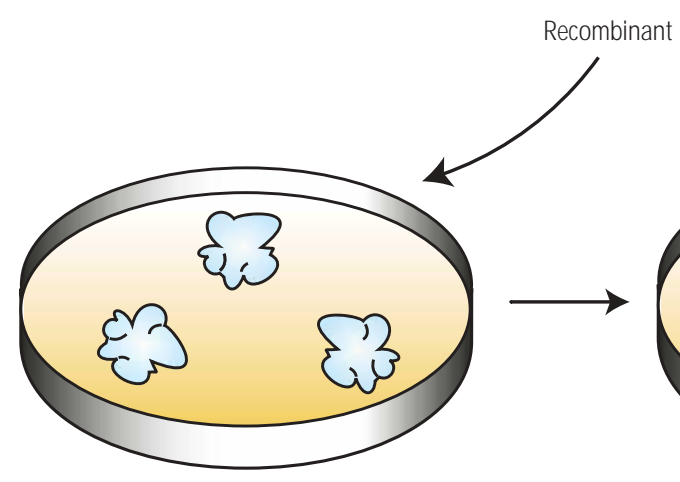

Only cells containing recombinant DNA survive and divide in culture on selective medium

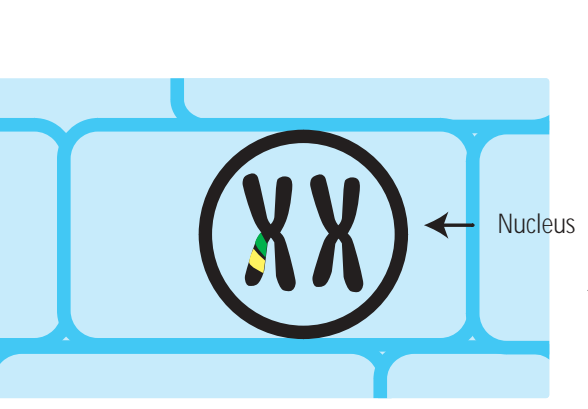

Recombinant DNA inserted into plant chromosome

Cells regenerate into transgenic plantlets

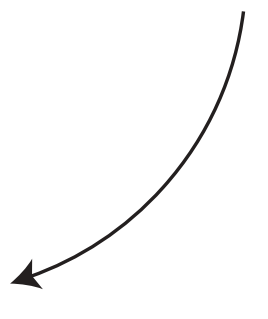

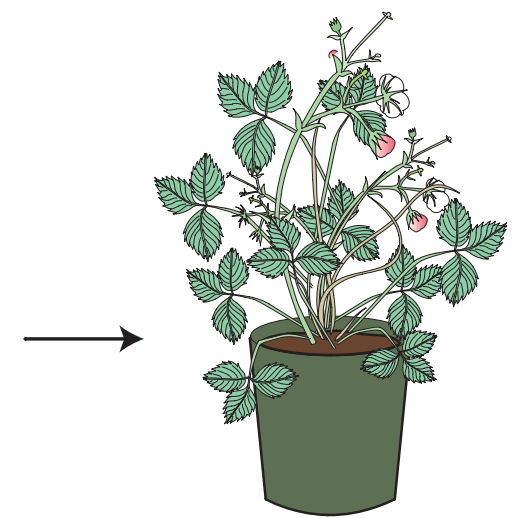

Plantlets grow into plants with new traits

Figure 9. Plant transformation and production of transgenic plants. Agrobacterium and biolistic methods can be used to transfer cloned genes into plant cells. Agrobacterium naturally transfers genes into plant chromosomes as part of its infection process, and this ability has been adapted by scientists to shuttle cloned genes into plants. In the biolistic method, the cloned DNA is coated onto microscopic beads that are then propelled into plant tissues. Some of the beads enter cells, and in some of these cells the DNA will be incorporated into the chromosomes. In both methods, tissue culture is then used to select and regenerate the transformed cells into fertile plants. 
can be used to increase expression of an existing characteristic or to decrease expression of an undesirable characteristic in a crop plant.

As in the DNA cloning process, a critical part of the transformation process is the selection of transgenic individuals, as only a small fraction of cells or seed is likely to have incorporated the desired transgene. This is generally done by incorporating a gene conferring resistance to an antibiotic and then selecting only plant cells that survive growth on the antibiotic (see fig. 9). Some people have raised concerns about whether the widespread use of such genes will increase the development of antibiotic resistance in human pathogens and make current medicines obsolete. However, the likelihood of this is extremely remote. The antibiotics used in plant transformation were chosen because they are seldom used in human or veterinary medicine. N onetheless, alternative types of marker genes have been developed and are replacing the antibiotic resistance method.

Transgenic plants are sometimes referred to as genetically modified organisms (GMOS). Despite the widespread use of this term, it is misleading because all of our domesticated plants and animals have been genetically modified using a variety of traditional and modern technologies, as described above. These plants can be described more precisely as "transgenic plants" or plants containing cloned genes.

Recombinant DNA and transformation techniques allow plant breeders to use genes from essentially any source as tools for crop improvement. For example, to enable rice grains to accumulate beta-carotene (which is converted into vitamin A when consumed by animals) and create the so-called "GoldenRice," scientists used genes from daffodil, pea, a bacterium, and a virus. Transgenic plant methods enable these four wellcharacterized genes to be inserted into a transgenic plant, producing a highly specific change in only the trait of interest. In contrast, many unknown genes are introduced when a breeder uses wide crosses to transfer a desired gene from a wild plant into a crop plant. For example, when the Mi gene for nematode resistance was transferred into tomato via wide crosses, the total amount of DNA exchanged was over 70 times larger than the Mi gene alone. Using the cloned Mi gene, only the nematode resistance trait would be introduced into other plants without transferring any additional DNA (and potentially undesirable traits) from the wild species. Woody tree and vine crops are difficult to improve by traditional breeding technology because it takes a number of years for a seedling to begin flowering, and the unique traits of specific varieties are hard to regain after sexual crosses. For example, some wine grape varieties have been propagated for hundreds of years by cuttings, since plants produced from seed will segregate for genetic traits, often losing the distinctive characteristics desired in the variety. On the other hand, if only one or a few genes could be transferred into a traditional variety, for example, to confer resistance to a disease or insect, the valuable genetic combination represented by the variety would be preserved. Thus, transgenic methods may be valuable tools for improvement of these woody crops that constitute a significant fraction of California's agricultural abundance.

\section{CONTINUING OPPORTUNITIES FOR CROP IMPROVEMENT}

Plant breeders have not exhausted the genetic resources available for crop improvement through traditional techniques, and recombinant DNA methods have now greatly expanded those potential resources. Transgenic crop varieties al ready on the market are providing value to farmers and consumers while reducing the use of agrochemicals and enabling production methods that reduce soil erosion. Other publications in the Agricultural Biotechnology in California Series will examine these products and the issues surrounding their use. 


\section{GLOSSARY}

Agrobacterium tumefaciens. A soilborne bacterium that can naturally transfer genetic information into plant cells, causing crown gall disease. This ability has been harnessed to transform (introduce desired sections of DNA into) many plant species.

anther culture. A method of producing haploid plants by aseptic culture of intact anthers or single pollen grains.

Arabidopsis thaliana. A small plant of the mustard family that is used as a model plant for genetic research; its chromosomes are small and it has a rapid life cycle ( 6 weeks from seed to flowering), making it well suited to genetic studies.

bacterium (pl., bacteria). A simple organism consisting of one cell or short chains of cells in which there is no nucleus. The chromosomal DNA is free within the cytoplasm as a single circular strand.

bases. The building blocks of DN A (adenine, thymine, cytosine, and guanine), which are strung together in specific sequences to encode genetic information.

biolistics. The insertion of DNA into plants by coating the DNA on tiny metal beads and propelling them at high speed into tissues; transformed plants can be regenerated from these single transgenic cells.

biotechnology. In the broadest sense, the use of living organisms or their vital processes or components to provide useful products. In the current modern usage, biotechnology is identified with techniques that collectively allow the precise identification, isolation, alteration, and reintroduction of heritable traits into living organisms for specific purposes.

callus. Undifferentiated plant cells growing in tissue culture that can often be induced to develop into complete embryos, roots, or shoots to regenerate complete plants.

chromosome. The organized structure containing DNA that carries genetic information. Humans have 23 pairs of chromosomes in their body (somatic) cells, one of each pair from each parent. Corn (maize) has 20 pairs, while tomato has 12.

clonal propagation of plants. To make identical copies of a particular plant by vegetative methods that include techniques known as tissue culture.

clone (of cells). Group of genetically identical cells arising from mitotic division.

clone (of DNA, as to clone a gene). To propagate and purify identical copies of a particular piece of DNA by enzymatic and biochemical techniques.

clone (of plants). A plant propagated vegetatively, as by the use of buds, or "eyes," of potatoes, or shoot or root cuttings. The resulting plants are genetically identical to the parent plants.

cultivar. A particular cultivated variety of a domesticated plant species.

DNA (deoxyribonucleic acid). In most organisms, DNA carries the primary genetic information. DNA is a molecule consisting of long chains of nucleotides. Each nucleotide consists of a base linked to a sugar (deoxyribose) and a phosphate molecule.

embryo culture (embryo rescue). The isolation of immature embryos from developing seeds and their culture in the laboratory to produce hybrid plants; primarily used in wide crosses between related species where normal seeds do not survive to maturity.

enzyme. A protein catalyst that speeds up a specific chemical reaction.

expression. The manifestation of a particular characteristic specified by a gene (not all genetically expressed traits are manifested by the organism, being masked by other dominant genes). Also, the activation of a gene leading to production of a protein. 
F1 hybrid. The offspring of a controlled cross between two inbred parents, resulting in the next generation having increased uniformity and vigor.

fingerprint (of DNA). A reproducible banding pattern created by a number of biochemical techniques of DNA isolation and/or amplification that clearly differentiate a genetic component in an individual, group, or population.

functional foods. Foods that provide a health benefit to the consumer beyond simply providing nutrition, such as lowering cholesterol or providing antioxidants.

gene. The basic unit of inheritance consisting of a sequence of DNA and generally occupying a specific position within the genome. Genes may be structural, which encode for particular proteins; regulatory, which control the expression of the other genes; or genes for transfer or ribosomal RNA.

genetic code. The groups of three nucleotide bases (codons) that specify a particular amino acid.

genetic engineering. The production of new combinations of genetic material by the modification of DNA outside of a cell and the subsequent transfer of the DNA into an organism in which the specific sequence of nucleotides does not naturally occur.

genetically modified organism (GMO). An organism that has been modified by the application of recombinant DN A technology.

genetics. The science of the transmission of characteristics between generations.

genome. The complete (haploid) set of chromosomes carried by a sex cell.

genotype. The total of all genetic information contained in an organism.

germplasm. Genetically distinct variants of a species that can represent a valuable natural resource of plant diversity.

graft. A plant bud, shoot, or scion that is inserted in a slit or groove in the stem or stock of another plant, where it continues to grow.

haploid. Plants containing only a single copy of each chromosome, such as the egg and pollen cells.

heterosis (hybrid vigor). Phenomenon in which the offspring of a cross between two distinct inbred parents exhibits increased growth (vigor) exceeding that of either parent.

heterozygous. Condition in which the two sets of chromosomes in an individual contain distinct genes at specific locations.

homologous (of chromosomes or DNA). Chromosomes that are highly similar due to relationship by descent but are not necessarily exact duplicates.

homozygous. Condition in which both sets of chromosomes in an individual contain essentially identical genes at all locations.

hybrid. The offspring of a specific cross between two genetically distinct (usually inbred) parents.

hybridization. Sexual cross between different individuals.

inbred. Condition in which both sets of chromosomes in an individual contain essentially identical genes (are homozygous) due to repeated self-pollination.

introgression. Transfer of a gene or trait from one individual to another by repeated back-crossing to the recurrent parent.

isozyme. Variant forms of an enzyme that can be reproducibly separated and identified, generally using starch gel electrophoretic procedures. Commercial labs routinely perform this procedure for genetic purity testing on a number of crops.

land race. An early, cultivated form of a crop species, evolved from a wild population. ligase. An enzyme capable of joining two DNA strands together.

linkage. The tendency of pairs or groups of genes to be inherited together because they are physically close within a single chromosome. 
male sterility. The inability of a plant to produce viable pollen; used in the production of hybrid seeds.

marker (genetic). A distinguishing feature that can be used to identify a particular gene location on a chromosome. Markers may be morphological (e.g., a physical trait such as growth habit, leaf form, color, flower shape); biochemical (e.g., isozymes, enzymes, or other proteins); or molecular (DNA fragment size or specific DNA sequences).

marker-assisted breeding. Use of DNA markers to increase the efficiency of selection in a population.

meristem. The growing points at the tips of roots and shoots in plants where new cells are created by cell division and subsequently develop into other plant tissues.

micropropagation. The mass production of clonal copies of a donor or parent plant by tissue culture techniques. The initial steps in micropropagation take place in synthetic solid or liquid growth media. Some processes can be conducted on a mass scale in culture tanks.

mutation. A random or directed change in the structure of DNA or chromosomes, often resulting in a visible or detectable trait alteration.

nucleus. The membrane-bound structure within eukaryotic cells that contains the chromosomes.

nutriceuticals. Components of foods that have nutritional or pharmaceutical benefits for the consumer, such as anticancer compounds, vitamin content, etc.

phenotype. Appearance or other characteristics of an organism that result from interactions of its genetic constitution with the environment.

plasmid. Circular DNA molecules that can be incorporated into and reproduced by bacteria as they multiply.

polymorphism. Individuals in a single species with different traits or DN A sequences.

protein. A molecule composed of a chain of many amino acids that acquires a particular folded shape due to the amino acid sequence. Both the sequence of the amino acids and the pattern of folding are involved in the specific function of the protein.

protoplast fusion. A protoplast is a plant cell from which the rigid outer cell wall has been removed; under certain conditions, protoplasts derived from genetically different plants can be fused, allowing their DN A (and other cellular contents) to be combined.

recombinant DNA. DNA formed external to a living cell by joining DNA from two or more different sources.

regenerate. To vegetatively reproduce a whole plant from single cells or isolated plant tissues.

restriction enzymes. Enzymes that can recognize specific DNA sequences and cut the DNA strands at those sites.

selectable marker. Gene whose expression allows the identification of a specific trait or gene in an organism.

self-pollination (self-fertilization). Process by which pollen of a given plant fertilizes the ovules of the same plant.

sequence (DNA or protein). The precise order of bases in a nucleic acid or of amino acids in a protein polypeptide.

sexual crosses. The transfer of pollen from one plant to the pistil of another closely related plant to result in seed that carry traits derived from both parents.

somaclonal variation. Genetic variation resulting from the process of culturing plant cells as callus and regenerating them back into whole plants.

technology. Applied science; a technical method of achieving a practical purpose. 
tissue culture. Regenerating a plant from single cells, isolated embryos, or small bits of plant tissue on liquid or solid media. The media are supplemented with a customized balance of nutrients and plant hormones known to induce the formation of roots, shoots, or both from disorganized plant tissue (callus).

totipotency. The capacity of a single cell to develop into a complete organism.

trait. A phenotypic characteristic associated with the expression of a single gene.

transformation. The process of introducing a cloned gene into an organism.

transgene, transgenic organism. An organism containing genetic material from other species introduced via the process of transformation.

vector. A piece of DNA that can be replicated when inserted into an appropriate host organism. Commonly used for gene cloning.

virus. A submicroscopic infectious agent that contains genetic material but must invade a cell in order to replicate itself.

wide crosses. Sexual crosses between related species to introduce additional genetic variation into crop plants.

\section{SOURCES OF ADDITIONAL INFORMATION}

ABC Series, Agricultural Biotechnology in California, http://sbc.ucdavis.edu/outreach/abc/abc_series.htm

Biotechnology Resource Series, Seed Biotechnology Center, UC Davis, http://sbc.ucdavis.edu/outreach/resource/resource_series.htm

Chrispeels, M. J., and D. E. Sadava. 2002. Plants, genes and agriculture. 2nd ed. Boston: Jones and Bartlett.

Newell M cGloughlin, M., and J. Burke. 2000. Biotechnology_Present position and future developments. Dublin, Ireland: Teagasc.

UCBiotech, University of California, Berkeley: http://ucbiotech.org 


\section{FOR MORE INFORMATION}

Visit our online catalog at http://anrcatalog.ucdavis.edu. You can also place orders by mail, phone, or fax, or request a printed catalog of publications, slide sets, and videos from

University of California

Agriculture and Natural Resources

Communication Services

6701 San Pablo Avenue, 2nd Floor

Oakland, California 94608-1239

Telephone: (800) $994-8849$ or (510) 642-2431

FAX: (510) 643-5470

E-mail inquiries: danrcs@ucdavis.edu

An electronic version of this publication is available on the DANR Communication Services website at http://anrcatalog.ucdavis.edu.

Publication 8043

(c) 2002 by the Regents of the University of California, Division of Agriculture and Natural Resources. All rights reserved.

Produced by the Seed Biotechnology Center, UC Davis, in cooperation with the Biotechnology Workgroup of the UC Division of Agriculture and Natural Resources.

The University of California prohibits discrimination against or harassment of any person employed by or seeking employment with the University on the basis of race, color, national origin, religion, sex, physical or mental disability, medical condition (cancer-related or genetic characteristics), ancestry, marital status, age, sexual orientation, citizenship, or status as a covered veteran (special disabled veteran, Vietnam-era veteran or any other veteran who served on active duty during a war or in a campaign or expedition for which a campaign badge has been authorized). University Policy is intended to be consistent with the provisions of applicable State and Federal laws.

Inquiries regarding the University's nondiscrimination policies may be directed to the Affirmative Action/Staff Personnel Services Director, University of California, Agriculture and Natural Resources, 300 Lakeside Drive, 6th Floor, Oakland, CA 94612-3550 (510) 987-0096. For a free catalog of other publications, call (800) 994-8849. For help downloading this publication, call (530) 754-5112.

To simplify information, trade names of products have been used. No endorsement of named or illustrated products is intended, nor is criticism implied of similar products that are not mentioned or illustrated.

pr-1/02-SB-CR

ISBN 978-1-60107-221-4 